\title{
Twenty years of robotic surgery: a challenge for human limits
}

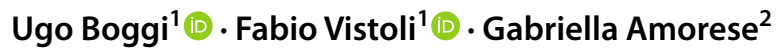

Received: 16 April 2021 / Accepted: 28 April 2021 / Published online: 21 May 2021

(c) The Author(s) 2021

Keywords da Vinci $\cdot$ Robotic surgery $\cdot$ Innovation $\cdot$ Development $\cdot$ Future perspectives

Leonardo Da Vinci means genius. Leonardo designed, and possibly built, the first articulated humanoid robot in 1495 in Milan (Italy) [1], but the term robot was coined only in 1921 by Karel Čapek, who staged a play with artificial people ("robota") working for humans in a factory [2]. Indeed, robots embody one of the main human dreams: having machines replacing man in dangerous or heavy tasks. In keeping with this hope, robots are machines conceived to aid, augment, or substitute humans.

Starting from the last two decades of the twentieth century, laparoscopy allowed surgeons to perform many procedures formerly requiring large incisions (i.e., open surgery) through keyhole openings, thus proportionally reducing surgical trauma. In open surgery, relatively large incisions are required to achieve good exposure of the surgical site and confidently address diseased tissues. Laparoscopic surgery (LS) not only made this possible, but also improved clinical outcomes and became the standard technique for many surgical procedures. However, implementation of conventional LS was limited in some complex operations, such as pancreatoduodenectomy or resection of hilar cholangiocarcinoma because of bidimensional vision, loss of hand-eye alignment, use of rigid instruments with a fulcrum effect and only 4 degrees of freedom, and poor surgeon ergonomics [3]. Robotic surgery, as provided by the da Vinci Surgical System (dVSS) (Intuitive Surgical, Sunnyvale, CA, USA), has been the following revolution in surgery, because this system was specifically designed to address most of the technical limitations of conventional LS. The dVss is a master-slave telemanipulator that faithfully reproduces the movements of

Ugo Boggi

u.boggi@med.unipi.it

1 Division of General and Transplant Surgery, University of Pisa, Pisa, Italy

2 Division of Anesthesia and Intensive Care, Azienda Ospedaliera Universitaria Pisana, Pisa, Italy surgeon's hands at tip of miniaturized intracorporeal instruments with seven degrees of freedom. Hand-eye coordination is also restored, thanks to an immersive view of the operative field that reproduces the natural alignment between vision, hands, and instruments. When all these features are taken together, the use of a dVSS restores the dexterity of open surgery in minimally invasive operations [4].

The dVSS was initially developed in the context of a military project of telesurgery, aiming to permit a remote surgeon to operate on wounded soldiers on a battlefield. The first robotic system was indeed integrated into a combat vehicle in 1994, and the first ex-vivo telesurgery procedure was performed during a combat exercise [5]. The first human operation, a cholecystectomy, was performed on March 3, 1997 by Himpens and Cadière [6]. In parallel with the dVSS, Zeus ${ }^{\circledR}$, another robotic system, was developed by a competing company (Computer Motion ${ }^{\circledR}$ ), but after several surgical procedures, this project was ended in 2003 when Computer Motion ${ }^{\circledR}$ merged with Intuitive Surgical ${ }^{\circledR}$. Several components of Zeus ${ }^{\circledR}$ were integrated in the subsequent versions of the dVSS. The first dVSS was sold to the Leipzig Heart Center in Germany in late 1998. The device obtained FDA clearance in 2000 [2].

Table 1 reports several first-ever robotic abdominal procedures performed using the dVSS. Time distribution of these procedures demonstrates that in 2003, only 3 years after FDA clearance, there was a peak in the number of reported new robotic operations, demonstrating quick uptake and confident use of the new technology in several different areas. It is also worth to note that some of these procedures were truly complex, such as distal splenopancreatectomy, pancreatoduodenectomy, total gastrectomy with D2 lymphadenectomy, rectal anterior resection, transhiatal esophagectomy, right extended hepatectomy, and radical cystectomy with intra-abdominal formation of orthotopic ileal neobladder. Other procedures, such as robotic pancreas transplantation and selective distal splenorenal shunt for the treatment of 
Table 1 First world abdominal procedures performed using a da Vinci surgical system ${ }^{\circledR}$

\begin{tabular}{|c|c|c|c|}
\hline First author (ref) & Journal-volume-year & Location & Type of procedure \\
\hline Himpens J & Surg Endosc_-12—1998 & Brussels, Belgium & Cholecystectomy \\
\hline Cadière GB & Ann Chir-53-1999 & Brussels, Belgium & Nissen fundoplication \\
\hline Cadière GB & Obes Surg—9—1999 & Brussels, Belgium & Gastric banding \\
\hline Loulmet D & J Thorac Cardiovasc Surg-118-1999 & Paris, France & Coronary artery bypass \\
\hline Abou CC & J Urol-165-2001 & Créteil, France & Radical prostatectomy \\
\hline Guillonneau B & J Urol—166-2001 & Paris, France & Nephrectomy \\
\hline Weber PA & Dis Colon Rectum—45-2002 & Hackensack, NJ, US & Sigmoid colectomy (benign disease) \\
\hline Weber PA & Dis Colon Rectum—45-2002 & Hackensack, NJ, US & Right hemicolectomy (benign disease) \\
\hline Hashizume M & Surg Endosc-16-2002 & Fukuoka, Japan & Ileocecal resection (cancer) \\
\hline Hashizume M & Surg Endosc_-16-2002 & Fukuoka, Japan & Distal gastrectomy (cancer) \\
\hline Hashizume M & Surg Endosc-16-2002 & Fukuoka, Japan & Splenectomy \\
\hline Hashizume M & Surg Endosc-16-2002 & Fukuoka, Japan & Sigmoid colectomy (cancer) \\
\hline Chapman WH 3rd & $\begin{array}{l}\text { J Laparoendosc Adv Surg Tech A-12- } \\
2002\end{array}$ & Greenville, NC, US & Splenectomy \\
\hline Desai MM & Urology-60-2002 & Cleaveland, OH, US & Adrenalectomy \\
\hline Ballantyne GH & JSLS-7-2003 & Hackensack, NJ, US & Ventral hernia repair \\
\hline Menon M & BJU Int-92-2003 & Detroit, MI, US & $\begin{array}{l}\text { Nerve-sparing robot-assisted radical cysto- } \\
\text { prostatectomy }\end{array}$ \\
\hline Melvin WS & $\begin{array}{l}\text { J Laparoendosc Adv Surg Tech A._-13- } \\
2003\end{array}$ & Columbus, $\mathrm{OH}, \mathrm{US}$ & Distal splenopancreatectomy \\
\hline Giulianotti PC & Arch Surg-138-2003 & Grosseto, Italy & Pancreatoduodenectomy \\
\hline Giulianotti PC & Arch Surg-138-2003 & Grosseto, Italy & Liver segmentectomy \\
\hline Giulianotti PC & Arch Surg-138-2003 & Grosseto, Italy & Resection of esophageal leiomyoma \\
\hline Giulianotti PC & Arch Surg-138-2003 & Grosseto, Italy & Total gastrectomy with D2 lymphadenectomy \\
\hline Giulianotti PC & Arch Surg-138-2003 & Grosseto, Italy & Gastric wedge resection \\
\hline Giulianotti PC & Arch Surg-138-2003 & Grosseto, Italy & Resection of common bile duct \\
\hline Giulianotti PC & Arch Surg-138-2003 & Grosseto, Italy & Rectal anterior resection \\
\hline Giulianotti PC & Arch Surg-138-2003 & Grosseto, Italy & Partial splenectomy \\
\hline Giulianotti PC & Arch Surg-138-2003 & Grosseto, Italy & Repair of splenic artery aneurysm \\
\hline Giulianotti PC & Arch Surg-138-2003 & Grosseto, Italy & Renal artery aneurysmectomy and bypass \\
\hline Melvin WS & Am J Surg-186-2003 & Columbus, OH, US & $\begin{array}{l}\text { Pancreaticojejenostomy (through an open } \\
\text { access) }\end{array}$ \\
\hline Horgan S & Am Surg-69-2003 & Chicago, IL, US & Transhiatal esophagectomy \\
\hline Molpus KL & JSLS-7-2003 & Omaha, NE, US & Ovarian transposition \\
\hline Vibert E & Arch Surg-138-2003 & Paris France & Right extended hepatectomy \\
\hline Beecken WD & Eur Urol—44-2003 & Frankfurt am Main, Germany & $\begin{array}{l}\text { Radical cystectomy with intra-abdominal } \\
\text { formation of orthotopic ileal neobladder }\end{array}$ \\
\hline Bentas W & World J Urol—21—2003 & Frankfurt, Germany & Anderson-Hynes pyeloplasty \\
\hline Kernstine KH & J Thorac Cardiovasc Surg-2004_2004 & Iowa City, Iowa, US & $\begin{array}{l}\text { 2-stage, 3-field robotic esophagolymphad- } \\
\text { enectomy }\end{array}$ \\
\hline Roeyen G & Surg Endosc_-18_-2004 & Edegem, Belgium & Choledochotomy \\
\hline Advincula AP & J Am Assoc Gynecol Laparosc_-11_2004 & Ann Arbor, MI, US & Uterine myomectomy \\
\hline Killewich LA & Vasc Endovascular Surg._-38-2004 & Galveston, TX, US & $\begin{array}{l}\text { Aorto-femoral bypass for aortoiliac occlusive } \\
\text { disease }\end{array}$ \\
\hline Gettman MT & Urology-64-2004 & Rochester, MI, US & Partial nephrectomy \\
\hline Melamud O & Urology-65-2005 & Orange, CA, US & Repair of vesicovaginal fistula \\
\hline Mohr CJ & Arch Surg-140-2005 & Stanford, CA, US & Roux-en-Y gastric bypass \\
\hline Ryska M & Rozhl Chir-85-2006 & Prague, Czech Republic & Robotic liver resection \\
\hline Mufarrij PW & Rev Urol-8-2006 & New York, NY, US & $\begin{array}{l}\text { Ureterolysis for idiopathic retroperitoneal } \\
\text { fibrosis }\end{array}$ \\
\hline Yee DS & Urology-68-2006 & Orange, California, US & Ureteroureterostomy \\
\hline
\end{tabular}


Table 1 (continued)

\begin{tabular}{|c|c|c|c|}
\hline First author (ref) & Journal—volume-year & Location & Type of procedure \\
\hline Sert B & Int J Med Robot—3-2007 & Oslo, Norway & Radical hysterectomy \\
\hline Jaik NP & J Gastrointestin Liver Dis_-16-2007 & Bethlehem, PA, US & Division of median arcuate ligament \\
\hline Tayar C & Surg Endosc_-21—2007 & Créteil Cedex, France & Mesh repair of incisional hernia \\
\hline Meehan JJ & J Pediatr Surg—42—2007 & Iowa City, IA, US & Repair of congenital duodenal atresia \\
\hline Korets R & Urology-70-2007 & New York, NY, US & Ureterocalicostomy \\
\hline Horgan $\mathrm{S}$ & Transplantation-84-2007 & Chicago, IL, US & $\begin{array}{l}\text { Segmental pancreas and kidney procurement } \\
\text { for live donor pancreas-kidney transplanta- } \\
\text { tion }\end{array}$ \\
\hline Meehan JJ & J Pediatr Surg—42-2007 & Iowa City, IA, US & $\begin{array}{l}\text { Repair of a Bochdalek congenital diaphrag- } \\
\text { matic hernia }\end{array}$ \\
\hline Choi SB ${ }^{\mathrm{a}}$ & Yonsei Med J—49—2008 & Seoul, South Korea & Left lateral sectionectomy \\
\hline Vasile $\mathrm{S}^{\mathrm{a}}$ & Chirurgia (Bucur) $-103-2008$ & Bucharest, Romania & Left lateral sectionectomy \\
\hline Berry $\mathrm{T}$ & J Robot Surg-2-2008 & Norfolk, VA, US & $\begin{array}{l}\text { Vaginal construction in Mayer-Rokitansky- } \\
\text { Küster-Hauser syndrome }\end{array}$ \\
\hline Wahlgren CM & Ann Vasc Surg-22-2008 & Chicago, IL, US & Repair of thoracoabdominal aortic aneurysm \\
\hline Gundeti MS & Urology $-72-2008$ & Chicago, IL, US & $\begin{array}{l}\text { Augmentation ileocystoplasty and Mitrofanoff } \\
\text { appendicovesicostomy }\end{array}$ \\
\hline Liu C & J Minim Invasive Gynecol—15-2008 & New York, NY, US & Partial bladder resection \\
\hline Anderberg M & Eur J Pediatr Surg—19—2009 & Lund, Sweden & Morgagni hernia repair \\
\hline Martinez BD & Ann Vasc Surg-23-2009 & Toledo, OH, US & Aorto-bifemoral graft bypass \\
\hline Park JS & $\begin{array}{l}\text { J Laparoendosc Adv Surg Tech A-19- } \\
2009\end{array}$ & Seoul, South Korea & $\begin{array}{l}\text { Resection of extra-adrenal pheochromocy- } \\
\text { toma }\end{array}$ \\
\hline Kumar A & J Endourol—23-2009 & New York, NY, US & Partial adrenalectomy \\
\hline Vasilescu C & J Endourol-23-2009 & Bucharest, Romania & Spleen-preserving distal pancreatectomy \\
\hline Geffner SR & Reported online only $-2009^{\mathrm{b}}$ & Livingston, NJ, US & Robotic kidney transplantation \\
\hline Patriti A & J Hepatobiliary Pancreat Surg-16-2009 & Spoleto, Italy & Simulatenous liver and colon resection \\
\hline Bütter A & J Robot Surg—4-2010 & London, Ontario, Canada & $\begin{array}{l}\text { Duodenojejunostomy for superior mesenteric } \\
\text { artery syndrome }\end{array}$ \\
\hline Giulianotti PC & $\begin{array}{l}\text { J Laparoendosc Adv Surg Tech A-20- } \\
2010\end{array}$ & Chicago, IL, US & $\begin{array}{l}\text { Extended hepatectomy plus hepaticojejunos- } \\
\text { tomy for hilar cholangiocarcinoma }\end{array}$ \\
\hline Giulianotti PC & Pancreas-40-2011 & Chicago, IL, US & Total pancreatectomy \\
\hline Zureikat & Arch Surg-146-2011 & Pittsburgh, PA, US & Frey procedure \\
\hline Buchs N & Int J Med Robot-7-2011 & Chicago, Illinois, US & Palliation of unresectable pancreatic cancer \\
\hline Boggi U & Transpl Int-26-2011 & Palermo, Italy & Purely robotic live donor right hepatectomy \\
\hline Giulianotti PC & Transpl Int-25-2012 & Chicago, Illinois, US & Hand-assisted live donor right hepatectomy \\
\hline Masrur M & JSLS-16-2012 & Chicago, IL, US & Subtotal pancreas-preserving duodenectomy \\
\hline Boggi U & Transplantation-93-2012 & Pisa, Italy & Pancreas transplantation \\
\hline Boggi U & Surgery-157-2015 & Pisa, Italy & $\begin{array}{l}\text { Distal selective spleno-renal shunt for severe } \\
\text { portal hypertension }\end{array}$ \\
\hline
\end{tabular}

${ }^{a}$ These authors simultaneously reported the same procedure in August 2008

${ }^{b}$ https://www.itnnews.co.in/indian-transplant-newsletter/issue27/WORLDS-First-Robot-Assisted-Kidney-Transplant-Performed-656.htm

severe portal hypertension, were so complex that were never performed using conventional LS. Geographical distribution of these first-ever procedures shows that nearly half of them were performed in the US and approximately one out of five in Italy (Fig. 1). As of December 31, 20195582 dVSS had been installed worldwide (3531 in the U.S., 977 in Europe, 780 in Asia, and 294 in the rest of the world). During 2019 over 1,200,000 dVSS surgeries were performed. Although in the common view, the dVSS is mostly used for urological procedures, according to US data, starting from 2018 general surgery procedures became prevalent [7]. General surgery is indeed the next great area of development of dVSS surgery. The need to use the robot in the wider anatomical field of general surgery, which increases variability and may include technically demanding procedures, has forced development of the system to increase flexibility in use.

The dVSS has still some technical limitations, mainly the need for a rigorous docking technique, longer operative 
Fig. 1 Number of first-ever reported robotic procedures by country. In the map, darker color represents higher number of first-ever reported robotic procedures in each country

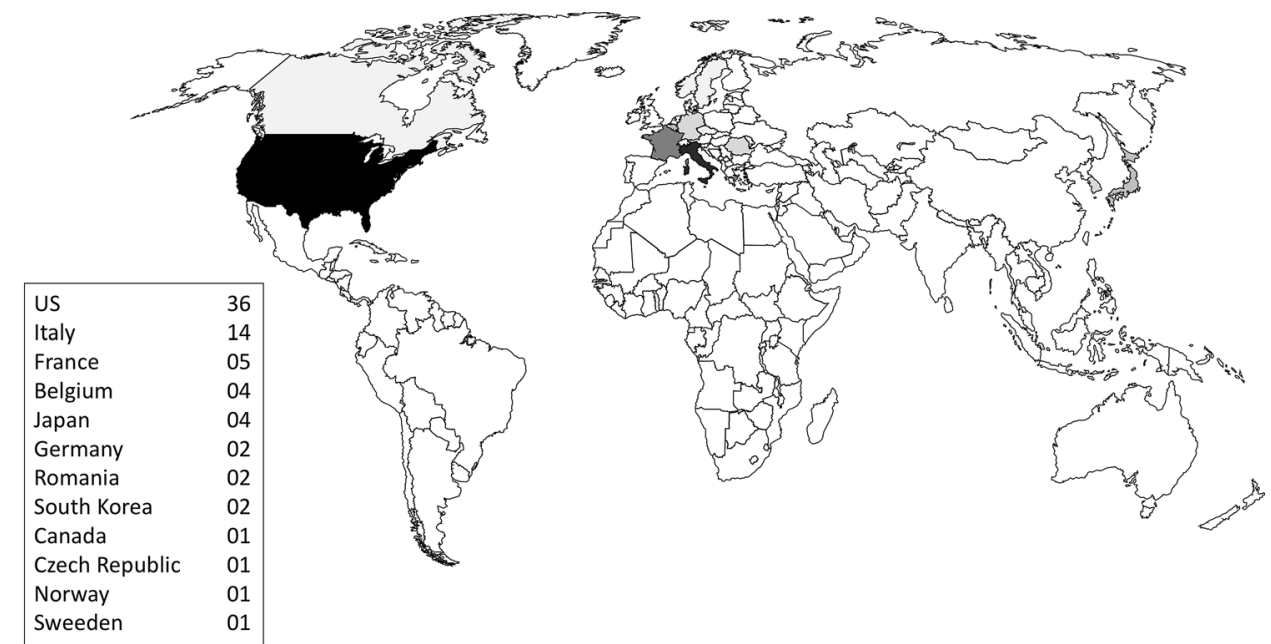

times, lack of haptic feedback, and high costs. Indeed, robotic assistance clearly increases operative costs because of additional expenditures caused by device amortization and maintenance, acquisition of robotic instruments, and longer occupancy of operative room. Most of the robotic procedures are actually hybrid procedures requiring laparoscopic or thoracoscopic assistance, thus further increasing overall costs [8].

From a mechanical point of view, the dVSS is close to perfection and carries only a small risk of malfunction. A recent publication on 10,267 dVSS procedures reported a mechanical failure rate of $1.8 \%(185 / 10,267)$. Most of these malfunctions were caused by instrument failures (130; $70.3 \%$ ) and were solved by replacing the malfunctioning instrument without consequences. In 7 patients, robotic malfunction required conversion to a different surgical approach $(0.06 \%)$. Three patients were converted to laparoscopic surgery and four to open surgery. The overall mortality rate was $0.12 \%(12 / 10,267)$ [9].

By all the above mentioned features, it is clear that robotic assistance in surgery is essential, especially for complex procedures requiring fine intracorporeal dissections and multiple or delicate reconstructions. In competent and trained hands, the dVSS permits effortless performance of very difficult intracorporeal maneuvers and increases their reproducibility by different surgeons. Robotic assistance facilitates also training of newer generations of surgeons, thanks to the availability of the dual console and the immediate restoration of hand-eye coordination permitting also novices to faithfully reproduce surgical maneuvers under supervision. In addition, the advent of robotic surgery had also some indirect, although important and transversal, implications. First, the international community recognized that the optimal use of robotic technology requires the development of dedicated training pathways and that outcomes during the learning curve should be scrutinized [10]. Second, implementation of robotic surgery on a large scale for procedures believed to be safely feasible only through an open approach, promoted refinements in open surgical technique to keep up with minimally invasive standards (such as reduced blood loss, and precise anatomical dissections). Third, availability of robotic surgery has prompted improvements in key technology used in conventional LS (e.g., $4 \mathrm{~K}$ and 3D vision systems).

In conclusion, robots and robotic surgery are both here to stay. Current surgical residents, who start their training in operating rooms equipped with robots, will grow up using surgical robots such as millennials use smartphones. As it has already happened for laparoscopic cholecystectomy, future generations of surgeons might not be familiar in performing some procedures other than robotically. Operating in virtual reality, when eventually available, will create a new dimension of surgery permitting precise preoperative planning. Anticipation of operative scenarios could also allow assignment of tasks based on simulated performance. It is indeed clear that the concept of robotic surgery, that could also be renamed computer-enhanced surgery [3], carries the germ of additional disruptive innovations that are expected to expand surgeon power beyond human capability. Additional and fascinating scenarios include integration of multiple technologies in a single surgical instrument, navigation, artificial intelligence, and autonomous robotic function.

As many patents hold by Intuitive Surgical will expire shortly, and other companies are developing newer devices, the market is expected to become competitive eventually reducing costs of robotic assistance. This will certify the final rise of robots in surgery. The intuition of Leonardo over 500 years ago is going to be turned into reality. 
Funding Open access funding provided by Università di Pisa within the CRUI-CARE Agreement. This manuscript did not receive any specific grant from funding agencies in public, commercial, or non-profit sectors.

Availability of data and material All materials are available upon request.

\section{Declarations}

Conflict of interest The authors declare that they have no conflict of interest.

Research involving human participants and/or animals It does not involve research with either humans or animals.

Informed consent Informed consent is not required.

Open Access This article is licensed under a Creative Commons Attribution 4.0 International License, which permits use, sharing, adaptation, distribution and reproduction in any medium or format, as long as you give appropriate credit to the original author(s) and the source, provide a link to the Creative Commons licence, and indicate if changes were made. The images or other third party material in this article are included in the article's Creative Commons licence, unless indicated otherwise in a credit line to the material. If material is not included in the article's Creative Commons licence and your intended use is not permitted by statutory regulation or exceeds the permitted use, you will need to obtain permission directly from the copyright holder. To view a copy of this licence, visit http://creativecommons.org/licenses/by/4.0/.

\section{References}

1. EllingRosheim M (2006) Leonardo's lost robots. Springer, Heidelberg
2. Pugin F, Bucher P, Morel P (2011) History of robotic surgery: from AESOP ${ }^{\circledR}$ and ZEUS ${ }^{\circledR}$ to da Vinci ${ }^{\circledR}$. J Visc Surg 148:e3-8. https://doi.org/10.1016/j.jviscsurg.2011.04.007

3. Leal Ghezzi T, Campos Corleta O (2016) 30 years of robotic surgery. World J Surg 40:2550-2557. https://doi.org/10.1007/ s00268-016-3543-9

4. Freschi C, Ferrari V, Melfi F, Ferrari M, Mosca F, Cuschieri A (2013) Technical review of the da Vinci surgical telemanipulator. Int J Med Robot 9:396-406. https://doi.org/10.1002/rcs.1468

5. Bowersox JC, Shah A, Jensen J et al (1996) Vascular applications of telepresence surgery: initial feasibility studies in swine. J Vasc Surg 23(2):281-287

6. Himpens J, Leman G, Cadiere GB (1998) Telesurgical laparoscopic cholecystectomy. Surg Endosc 12(8):1091. https://doi.org/ $10.1007 / \mathrm{s} 004649900788$

7. https://www.annualreports.com/Company/intuitive-surgical-inc. Accessed February 1,2021

8. Turchetti G, Palla I, Pierotti F, Cuschieri A (2012) Economic evaluation of da Vinci-assisted robotic surgery: a systematic review. Surg Endosc 26:598-606. https://doi.org/10.1007/ s00464-011-1936-2

9. Koh DH, Jang WS, Park JW, Ham WS, Han WK, Rha KH, Choi YD (2018) Efficacy and safety of robotic procedures performed using the da Vinci robotic surgical system at a single institute in Korea: experience with 10000 cases. Yonsei Med J 59:975-981. https://doi.org/10.3349/ymj.2018.59.8.975

10. Hogg ME, Besselink MG, Clavien PA, Fingerhut A, Jeyarajah DR, Kooby DA, Moser AJ, Pitt HA, Varban OA, Vollmer CM, Zeh HJ 3rd, Hansen P, Committee MIPRO (2017) Training in minimally invasive pancreatic resections: a paradigm shift away from "see one, do one, teach one." HPB (Oxford) 19:234-245. https://doi. org/10.1016/j.hpb.2017.01.016

Publisher's Note Springer Nature remains neutral with regard to jurisdictional claims in published maps and institutional affiliations. 